\title{
HIV TESTING AMONG PEOPLE WHO INJECT DRUGS IN IVANOVO AND NOVOSIBIRSK, RUSSIA
}

\author{
Elizabeth J. King ${ }^{1,2}$, Linda M. Niccolai ${ }^{2}$, Ksenia U. Eritsyan ${ }^{3}$, Robert Heimer ${ }^{2}$, Olga S. Levina ${ }^{3}$ \\ ${ }^{1}$ Department of Health Behavior and Health Education, University of Michigan School of Public Health, Ann Arbor, Michigan, USA \\ ${ }^{2}$ Yale School of Public Health and Center for Interdisciplinary Research on AIDS, New Haven, Connecticut, USA \\ ${ }^{3} \mathrm{NGO}$ Stellit, St. Petersburg, Russia
}

\begin{abstract}
SUMMARY
Objective: HIV testing among people who inject drugs (PWID) in Russia has been documented to be low; however, few studies have been conducted outside of the major metropolitan cities. The aim of this study was to determine how many PWID were aware of their HIV serostatus and what motivators were associated with getting tested for HIV.

Methods: Our analysis describes HIV testing behaviours among 593 PWID in Ivanovo and Novosibirsk, Russia. Participants completed a questionnaire and consented to HIV testing. We used logistic regression modelling to determine demographic and behavioural correlates of HIV testing.

Results: Self-reported history of HIV testing was $52 \%$ in Ivanovo and $54 \%$ in Novosibirsk. Prior knowledge of serostatus was very low among PWID who tested positive ( 3 of 102 in Ivanovo and 0 of 11 in Novosibirsk). The most common reason for testing was doctor referral, and the most common locations were government HIVIAIDS centres and prisons. HIV testing was rarely client initiated or led by a personal motivation for being tested.

Conclusions: HIV testing in Ivanovo and Novosibirsk is suboptimal, resulting in poor knowledge of HIV serostatus. More programmes to promote HIV testing among PWID are urgently needed in both cities.
\end{abstract}

Key words: Russia, Novosibirsk, Ivanovo, people who inject drugs, HIV testing, HIV serostatus, knowledge

Address for correspondence: E. J. King, Department of Health Behavior and Health Education, University of Michigan School of Public Health, 1415 Washington Heights, Ann Arbor, Michigan, USA. E-mail: ejking@umich.edu

https://doi.org/10.21101/cejph.a4831

\section{INTRODUCTION}

Universal access to HIV testing is essential for maximizing linkage to treatment and preventing HIV transmission $(1,2)$. Additionally, there is strong evidence to suggest that people who inject drugs (PWID) adopt behaviours to reduce transmission to their drug using partners after they are diagnosed with HIV (3). Unfortunately, HIV testing has been suboptimal in many parts of the world, including Russia. Although Russia has the largest HIV epidemic concentrated among PWID (4) and HIV prevalence among PWID in some Russian cities exceeds 50\%, there has been little effort to target HIV testing to PWID except for those entering prison or drug detoxification programmes (5-9).

Second generation bio-behavioural surveys have been used to explore HIV prevalence among PWID in as many as 13 Russian cities, but only limited attention has been paid to assessing the extent of testing and awareness of HIV serostatus by those undergoing testing. To redress this, we analysed bio-behavioural data collected in two Russian cities, Ivanovo and Novosibirsk. These places were selected because targeted surveillance of the most-at-risk PWID population was lacking and less is known about the HIV epidemic and prevalence of injection drug use in these cities in Russia. Our surveillance among PWID detected the HIV prevalence to be $34.0 \%$ in Ivanovo and 3.8\% in Novosibirsk (10). Ivanovo, located northeast of Moscow, is a moderate sized city with a population of $\sim 400,000$ and has an HIV prevalence of
$0.5 \%$ in the general population (11). Novosibirsk is the third largest city in Russia located in the Siberian region with a population of 1.4 million and a similar HIV prevalence of $0.5 \%$ in the general population (11). Our research objective for this manuscript was to determine how many PWID were aware of their HIV serostatus and what motivators were associated with getting tested for HIV.

\section{MATERIALS AND METHODS}

Our data came from a larger study that was designed to explore the social, psychological and behavioural characteristics of people affected by HIV in Ivanovo and Novosibirsk. We used respondent-driven sampling, a modified form of peer-referral that uses a dual incentive structure, only as a tool to improve efficiency in the recruitment of our convenience sample. PWID were eligible to participate if they were 18 years of age or older, provided written informed consent, and had injected any drugs during the past 30 days. Initial participants ( $\mathrm{n}=11$ in Ivanovo, $\mathrm{n}=$ 10 in Novosibirsk) were recruited by local fieldworkers from their network of contacts at drug treatment, harm-reduction, and AIDS advocacy service organizations. Participants were compensated for their time at the end of the study visit with a gift of food and personal hygiene products valued at 200 roubles (approximately US\$7.00 at the time of data collection). PWID who successfully recruited others to the study were given gifts equivalent to 200 
roubles per new recruit. Ethical approval was obtained from the institutional review boards at all participating sites. To ensure anonymity, participants were assigned unique codes that linked the surveys with HIV test results. Participants were able to obtain their test results using this code, and these codes also helped to ensure PWID participated in the study only once.

All participants completed an interviewer-administered questionnaire in a private space. The interviewer-administered questionnaire was adapted from instruments used in previous studies conducted in Russia and included questions about sociodemographic information, current and past drug use, sexual behaviours, and previous HIV testing. Venous blood specimens were tested for HIV antibodies by the standard primary and confirmatory tests used by all Russian AIDS centres (12).

Statistical analyses were conducted separately for Ivanovo and Novosibirsk because they are geographically and historically distinct and because the HIV prevalence among PWID was so different (34\% in Ivanovo and 3.8\% in Novosibirsk). The primary outcome for this analysis was self-report of having ever had an HIV test. Other HIV testing variables included time since last test, receiving results, test results, and whether testing was voluntary. We hypothesised that the locations and correlates of testing may also differ for the two cities. Unadjusted and adjusted demographic and behavioural correlates of HIV testing were determined with logistic regression modelling. Adjusted odds ratios (aOR) and $95 \%$ confidence intervals $(\mathrm{CI})$ were derived by initially including all covariates significant at $\mathrm{p}<0.20$ in a multivariate model and then using backward selection to generate the most parsimonious model that contained only covariates statistically significant at the $\mathrm{p}<0.05$ level.

\section{RESULTS}

A total of 593 PWID (300 from Ivanovo and 293 from Novosibirsk) participated in this study. The sample was predominantly male ( $76 \%$ in Ivanovo and $68 \%$ in Novosibirsk) with a median age of 25 years in both cities. The median age at first injection drug use was 18 in Ivanovo and 20 in Novosibirsk. In Ivanovo, only 3 of those who tested positive for HIV reported knowing they were HIV positive (2.9\%). In Novosibirsk, none of those who tested positive for HIV reported knowing they were HIV positive. Of the 113 who tested positive for HIV in our study, 61 (54\%) reported ever being tested in the past. Table 1 presents the testing patterns of study participants. Testing knowledge and patterns were similar in the two cities for all variables included in the survey.

The most common reason for testing in both cities was referral by doctor ( $46 \%$ in Ivanovo and $45 \%$ in Novosibirsk). In Ivanovo, the next most common reasons were health certificate requirement $(21 \%)$, risky injection drug use $(9 \%)$, and going with a friend (7\%); all other reasons were cited by less than $5 \%$ of participants. In Novosibirsk, the next most common reasons were risky injection drug use (14\%), health certificate requirement (13\%), going with a friend (13\%), and risky sexual behaviours ( $9 \%)$. All other reasons were cited by less than $5 \%$ of participants. In both cities, the most commonly reported location for HIV testing was an AIDS centre (28\% in Ivanovo and $25 \%$ in Novosibirsk) followed by jail or prisons ( $17 \%$ in Ivanovo and $24 \%$ in Novosibirsk). In Ivanovo, the next most common locations were maternity centres
(14\%) and outpatient clinics (12\%). In Novosibirsk, the next most common locations were sexual health clinics (14\%) and outpatient clinics (12\%). All other locations were reported by less than $10 \%$ of participants.

Adjusted correlates of HIV testing are presented in Table 2. In Ivanovo, higher education (aOR 2.20, 95\% CI 1.18-4.12), having paid for sex (aOR 3.86, 95\% CI 1.48-10.1), and having sold sex (aOR 4.88, 95\% CI 1.57-15.2) were independent correlates of

Table 1. HIV testing: history, self-reported status and knowledge $(N=593)$

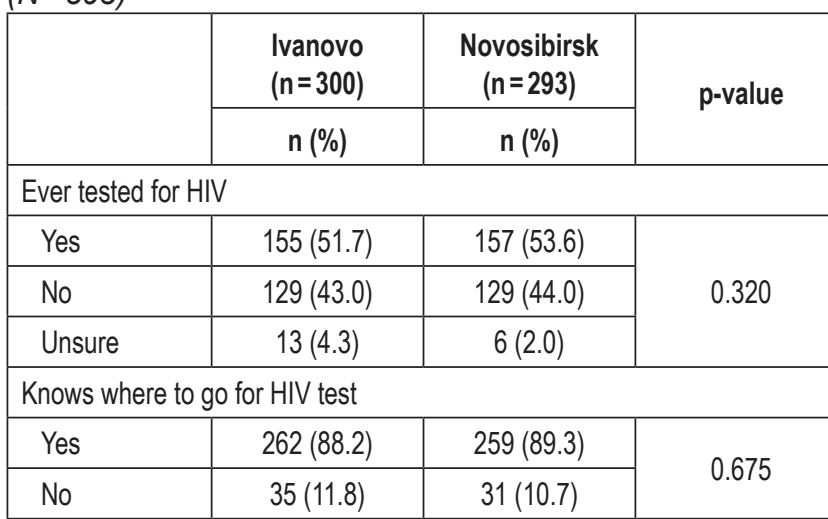

\begin{tabular}{|c|c|c|c|}
\hline \multicolumn{4}{|l|}{ Knows where to get free HIV test } \\
\cline { 1 - 3 } Yes & $249(83.0)$ & $243(82.9)$ & \multirow{2}{*}{0.983} \\
\hline No & $51(17.0)$ & $50(17.1)$ & \\
\hline
\end{tabular}

Knows where to get anonymous HIV test

\begin{tabular}{|c|c|c|c|}
\hline Yes & $216(72.0)$ & $199(67.9)$ & \multirow{2}{*}{0.278} \\
\cline { 1 - 3 } No & $84(28.0)$ & $94(32.1)$ & \\
\hline \multicolumn{3}{|c|}{ Knows where to get STI/HIV information } \\
\cline { 1 - 2 } Yes & $82(27.3)$ & $91(31.1)$ & \multirow{2}{*}{0.318} \\
\hline No & $218(72.7)$ & $202(68.9)$ & \\
\hline
\end{tabular}

Well-informed about HIV

\begin{tabular}{|l|l|c|c|}
\hline Yes & $98(52.1)$ & $99(49.5)$ & \multirow{2}{*}{0.871} \\
\cline { 1 - 3 } No & $90(47.9)$ & $101(50.5)$ & \\
\hline
\end{tabular}

Among those ever tested $(n=312)$

Self-reported HIV+ status

\begin{tabular}{|l|c|c|}
\hline Yes & $7(4.8)$ & $12(8.2)$ \\
\hline No & $139(94.6)$ & $130(88.4)$ \\
\hline Unsure & $1(0.7)$ & $4(2.7)$ \\
\hline
\end{tabular}

Time of most recent HIV test

\begin{tabular}{|l|l|l|}
\hline < 1 year ago & $35(22.6)$ & $38(24.2)$ \\
\hline 1-2 years ago & $42(27.1)$ & $38(24.2)$ \\
\hline 2-4 years ago & $39(25.2)$ & $41(26.1)$ \\
\hline >4 years ago & $38(24.5)$ & $40(25.5)$ \\
\hline
\end{tabular}

\begin{tabular}{|l|c|c|c|}
\hline \multicolumn{3}{|l|}{ Voluntary test } \\
\cline { 1 - 3 } Yes & $127(84.7)$ & $119(76.8)$ & \multirow{2}{*}{0.393} \\
\hline No & $27(15.3)$ & $36(23.2)$ & \\
\hline \multicolumn{2}{|l|}{ Received results } \\
\cline { 1 - 2 } Yes & $146(94.2)$ & $146(93.6)$ & \multirow{2}{*}{0.460} \\
\hline No & $6(3.9)$ & $9(5.7)$ & \\
\hline Unsure & $3(1.9)$ & $1(0.6)$ & \\
\hline
\end{tabular}


Table 2. Correlates of HIV testing: unadjusted and adjusted results $(N=593)$

\begin{tabular}{|c|c|c|c|c|c|c|c|c|}
\hline \multirow[b]{2}{*}{ Characteristic } & \multicolumn{4}{|c|}{ Ivanovo $(n=300)$} & \multicolumn{4}{|c|}{ Novosibirsk $(n=293)$} \\
\hline & $\mathrm{n}(\%)$ & $\begin{array}{l}\text { Tested } \\
\mathrm{n}(\%)\end{array}$ & $\begin{array}{l}\text { Bivariate } \\
\text { p-value }\end{array}$ & $\begin{array}{c}\text { Adjusted } \\
\text { OR }(95 \% \mathrm{Cl})\end{array}$ & $n(\%)$ & $\begin{array}{l}\text { Tested } \\
\mathrm{n}(\%)\end{array}$ & $\begin{array}{l}\text { Bivariate } \\
\mathrm{p} \text {-value }\end{array}$ & $\begin{array}{c}\text { Adjusted } \\
\text { OR (95\% Cl) }\end{array}$ \\
\hline \multicolumn{9}{|l|}{ Age } \\
\hline$\leq 25$ & $151(50.3)$ & $84(59.6)$ & \multirow{2}{*}{0.093} & & $169(57.7)$ & $86(52.8)$ & \multirow{2}{*}{0.404} & \\
\hline$>25$ & $149(49.7)$ & $71(49.7)$ & & & $124(42.3)$ & $71(57.7)$ & & \\
\hline \multicolumn{9}{|c|}{ Permanent residence in city } \\
\hline Yes & $298(99.7)$ & $153(54.3)$ & \multirow{2}{*}{0.999} & & $261(89.1)$ & $136(53.5)$ & \multirow{2}{*}{0.196} & \\
\hline No & $1(0.3)$ & $1(100.0)$ & & & $32(10.9)$ & $21(65.6)$ & & \\
\hline \multicolumn{9}{|c|}{ Educational background } \\
\hline $\begin{array}{l}\text { Secondary } \\
\text { education or less }\end{array}$ & $222(74.5)$ & $106(50.5)$ & \multirow[t]{2}{*}{0.017} & \multirow{2}{*}{$\begin{array}{c}1.0 \\
2.20(1.18,4.12)\end{array}$} & $243(83.5)$ & $131(55.3)$ & \multirow[t]{2}{*}{0.793} & \\
\hline University degree & $76(25.5)$ & $48(66.7)$ & & & $48(16.5)$ & $25(53.2)$ & & \\
\hline \multicolumn{9}{|l|}{ Employed } \\
\hline Yes & $188(62.7)$ & $92(51.4)$ & \multirow{2}{*}{0.160} & & $203(69.3)$ & $103(52.3)$ & \multirow{2}{*}{0.187} & \\
\hline No & $112(37.3)$ & $63(60.0)$ & & & $90(30.7)$ & $54(60.7)$ & & \\
\hline \multicolumn{9}{|l|}{ Ever in jail/prison } \\
\hline Yes & $56(18.8)$ & $21(39.6)$ & \multirow{2}{*}{0.015} & & $47(16.2)$ & $21(44.7)$ & \multirow{2}{*}{0.136} & \\
\hline No & $242(81.2)$ & $133(58.1)$ & & & $243(83.8)$ & $134(56.5)$ & & \\
\hline \multicolumn{9}{|c|}{ HIV+ person in drug network } \\
\hline Yes & $59(25.0)$ & $27(50.0)$ & \multirow{3}{*}{0.047} & & $8(3.0)$ & $5(62.5)$ & \multirow{3}{*}{0.824} & \\
\hline No & $23(9.7)$ & $17(81.0)$ & & & $95(35.4)$ & $52(55.9)$ & & \\
\hline Don't know & $154(65.3)$ & $74(50.3)$ & & & $165(61.6)$ & $86(54.1)$ & & \\
\hline \multicolumn{9}{|c|}{ Number of sex partners (12 months) } \\
\hline$\leq 1$ & $125(48.3)$ & $54(45.8)$ & \multirow{2}{*}{0.008} & & $118(44.7)$ & $56(48.7)$ & \multirow{2}{*}{0.148} & \\
\hline$>1$ & $134(51.7)$ & $79(62.7)$ & & & $146(55.3)$ & $82(57.7)$ & & \\
\hline \multicolumn{9}{|c|}{ Paid for sex (past 12 months) } \\
\hline Yes & $31(11.9)$ & $24(80.0)$ & \multirow{2}{*}{0.003} & \multirow{2}{*}{$\begin{array}{c}3.86(1.48,10.1) \\
1.0\end{array}$} & $40(15.0)$ & $33(82.5)$ & $<0001$ & $4.89(2.07,11.49)$ \\
\hline No & $230(88.1)$ & $110(50.9)$ & & & $227(85.0)$ & $108(49.1)$ & $<.001$ & 1.0 \\
\hline Sold sex (past $12 \mathrm{~m}$ & ths) & & & & & & & \\
\hline Yes & $22(8.5)$ & $18(81.8)$ & 0006 & $4.88(1.57,15.2)$ & $8(3.0)$ & $8(100.0)$ & م008 & \\
\hline No & $236(91.5)$ & $113(51.1)$ & 0.000 & 1.0 & $257(97.0)$ & $131(52.4)$ & 0.000 & \\
\hline $\mathrm{HIV}+$ sex partners $(\mathrm{p}$ & st 12 months) & & & & & & & \\
\hline Yes & $10(4.2)$ & $10(100.0)$ & & & $10(4.1)$ & $4(40.0)$ & & \\
\hline No & $62(25.9)$ & $25(43.1)$ & 0003 & & $80(32.8)$ & $46(59.0)$ & 0.471 & \\
\hline $\begin{array}{l}\text { Don't know/ } \\
\text { unsure }\end{array}$ & $167(69.9)$ & $88(55.3)$ & & & $154(63.1)$ & $80(53.7)$ & & \\
\hline
\end{tabular}

Only bivariates included in the multivariate model ( $p \leq 0.2$ in either city) are listed in this table.

having tested for HIV. In Novosibirsk, only having paid for sex (aOR 4.89, 95\% CI 2.07-11.49) was an independent correlate.

\section{DISCUSSION}

HIV testing rates among PWID are low in Ivanovo and Novosibirsk with approximately half in each city reporting having ever been tested and only an eighth tested in the previous year. These results differ from published results on HIV testing rates among PWID in other Russian cities. Between half and three-quarters of PWID had been tested in the past year in the cities of St. Peters- burg, Moscow, Barnaul, and Volgograd $(5,8)$. In our study, three out of 113 HIV-positive participants $(<3 \%)$ correctly knew their serostatus. In contrast, estimates of correct knowledge of HIVpositive serostatus range from $20 \%$ in Omsk to $70 \%$ in Orel (7). Lower rates of testing in Ivanovo and Novosibirsk may be due to lower perceived risk because the epidemics are not as advanced as in the other cities, but also because of fewer outreach services and HIV prevention activities. Ivanovo is one of the regions most affected by HIV in Russia, and Novosibirsk is now among the regions with the highest rates of new HIV diagnoses in Russia (11). While there are national-level HIV prevention campaigns through the Federal AIDS Centre, much of the work is done locally through 
both government institutions (for example, City AIDS Centres) and non-governmental organizations. This may also account for some of the regional differences in uptake of HIV testing.

Despite the high proportion of individuals who report knowing where to get free or anonymous HIV testing, the reported reasons for and locations of HIV testing suggest reasons for low testing rates. For example, the second most common location of testing was prisons, where HIV testing is mandatory. Furthermore, the top two reasons for testing - doctor referral and requirement to get a health certificate - suggest that testing, although voluntary, is not usually client initiated or led by a personal motivation for being tested. Instead, HIV testing is part of required medical or bureaucratic protocols in which a health certificate showing HIVnegative status is required for certain forms of employment or admission into a hospital. There were few behavioural correlates of HIV testing in the final multivariable model. The one exception to this is commercial sex; however, this behaviour was uncommon (reported by $<15 \%$ of participants) and hence may have limited implications for improving HIV testing uptake.

There may also be structural factors that contribute to the low HIV testing rates among PWID in Ivanovo and Novosibirsk. However, a thorough exploration of these was beyond the scope of our study. A previous study in another Russian city (Yekaterinburg) has demonstrated that PWID do not feel they have access to antiretroviral therapy because of their drug use and cannot address their drug use because of inadequate drug rehabilitation services (13). HIV-related stigma in Russia reduces the desire to get tested for HIV (14). PWID do not use drug treatment services due to fear of drug user registration systems, financial constraints, and the belief that the services are inadequate (15). Another study has found that women who are involved in drug use and sex work do not access HIV services, in part because of fear of being registered as a drug user (16). Further exploration of structural barriers to HIV testing and in-depth analyses of the social and cultural contexts are essential in both Ivanovo and Novosibirsk.

Our study had several limitations. First, the convenience sampling strategy limits our ability to know the extent to which our sample of PWID is representative. The high level of knowledge about testing opportunities found in our study may be a consequence of this sampling strategy. It could be that PWID, who are not well connected to services or other PWID, were not reached in our study. It may also be that men were over-recruited compared to women; gender differences among PWID warrant further exploration. Second, our study is cross-sectional. Therefore, any interpretations about causality and temporality are limited. Third, our study did not explore reasons for not being tested for HIV. This was a limitation in interpreting our findings and clearly warrants further exploration in future studies in Ivanovo and Novosibirsk, and indeed throughout Russia.

Relative to other cities in Russia, HIV testing rates and knowledge of positive serostatus were markedly lower in Ivanovo and Novosibirsk. Clearly, there is room and reason to increase HIV testing for PWID in these cities. While increasing opportunities for testing is important, it is critical to ensure that the process is informed and voluntary and that referrals for treatment and counselling are made. Our study results also serve as an example for the need to conduct studies outside of capital, metropolitan cities in order to document where programmes for HIV prevention and improvement in HIV testing and counselling should be further developed.

\section{Acknowledgement}

This research was funded by the Civilian Research and Development Foundation (CRDF 47.079 Levina and Heimer). EJK was supported by the Postdoctoral Training Grant at Yale University's Center for Interdisciplinary Research on AIDS (T32MH020031) from the National Institute of Mental Health. The content of the manuscript is solely the responsibility of the authors and does not necessarily represent the views of the funding agencies.

\section{Conflict of Interests}

None declared

\section{REFERENCES}

1. WHO/UNAIDS. Guidance on provider-initiated HIV testing and counselling in health facilities. Geneva: World Health Organization; 2007.

2. Cohen J. Breakthrough of the year. HIV treatment as prevention. Science. 2011 Dec 23;334(6063):1628.

3. Des Jarlais DC, Perlis T, Arasteh K, Hagan H, Milliken J, Braine N, et al. "Informed altruism" and "partner restriction" in the reduction of HIV infection in injecting drug users entering detoxification treatment in New York City, 1990-2001. J Acquir Immune Defic Syndr. 2004 Feb 1;35(2):158-66.

4. UNAIDS. Russian Federation County Situation 2009 [Internet]. Geneva: UNAIDS; 2009 [cited 2019 Jan 1]. Available from: http://www.unaids. org/ctrysa/EURRUS en.pdf.

5. Niccolai LM, Toussova OV, Verevochkin SV, Barbour R, Heimer R, Kozlov AP. High HIV prevalence, suboptimal HIV testing, and low knowledge of HIV-positive serostatus among injection drug users in St. Petersburg, Russia. AIDS Behav. 2010 Aug;14(4):932-41.

6. Grau LE, White E, Niccolai LM, Toussova OV, Verevochkin SV, Kozlov $\mathrm{AP}$, et al. HIV disclosure, condom use, and awareness of HIV infection among HIV-positive, heterosexual drug injectors in St. Petersburg, Russian Federation. AIDS Behav. 2011 Jan;15(1):45-57.

7. Eritsyan K, Heimer R, Barbour R, Odinokova V, White E, Rusakova MM, et al. Individual-level, network-level and city-level factors associated with HIV prevalence among people who inject drugs in eight Russian cities: a cross-sectional study. BMJ Open. 2013 Jun 20;3(6). pii: e002645.

8. Rhodes T, Platt L, Maximova S, Koshkina E., Latishevskaya N, Hickman $\mathrm{M}$, et al. Prevalence of HIV, hepatitis $\mathrm{C}$ and syphilis among injecting drug users in Russia: a multi-city study. Addiction. 2006 Feb;101(2):252-66.

9. Platt L, Rhodes T, Hickman M, Mikhailova L., Lisetsky K, Sarang A, et al. Changes in HIV prevalence and risk among new injecting drug users in a Russian city of high HIV prevalence. J Acquir Immune Defic Syndr. 2008 Apr 15;47(5):623-31.

10. Eritsyan KU, Levina OS, White E, Smolskaya TT, Heimer R. HIV prevalence and risk behavior among injection drug users and their sex partners in two Russian cities. AIDS Res Hum Retroviruses. 2013 Apr;29(4):687-90.

11. Pokrovsky VV, Ladnaya NN, Sokolova EV, Buravtsova EV. HIV Infection. Information bulletin No. 35. Moscow: Russian Federal AIDS Center; 2012. (In Russian.)

12. Smolskaya T, Liitsola K, Zetterberg V, Golovanova E, Kevlova N, Konovalova N, et al. HIV epidemiology in the Northwestern Federal District of Russia: dominance of HIV type 1 subtype A. AIDS Res Hum Retroviruses. 2006 Nov;22(11):1074-80.

13. Sarang A, Rhodes T, Sheon N. Systemic barriers accessing HIV treatment among people who inject drugs in Russia: a qualitative study. Health Policy Plan. 2013 Oct;28(7):681-91

14. Balabanova Y, Coker R, Atun RA, Drobniewski, F. Stigma and HIV infection in Russia. AIDS Care. 2006 Oct; 18(7):846-52.

15. Bobrova N, Rhodes T, Power R, Alcorn R, Neifeld E, Krasiukov N, et al. Barriers to accessing drug treatment in Russia: a qualitative study among injecting drug users in two cities. Drug Alcohol Depend. 2006 Apr;82 Suppl 1:S57-63.

16. King EJ, Maman S. Structural barriers to receiving health care services for female sex workers in Russia. Qual Health Res. 2013 Aug;23(8):1079-88. 